\title{
Assessment of Institution Readiness in Adopting Technology: A Study on Vocational Education Internal Quality Assurance System
}

\author{
Y Yulherniwati ${ }^{1}$, A Ikhsan ${ }^{2}$ \\ Department of Information Technology, Padang State Polytechnic, Kampus Limau Manis, \\ Padang, Indonesia ${ }^{1}$ \\ Department of Industrial Engineering, Bung Hatta University, Gunung Pangilun, Padang, \\ Indonesia $^{2}$ \\ \{ heni32@yahoo.com ${ }^{1}$, aidilikhsan@yahoo.com $\left.{ }^{2}\right\}$
}

\begin{abstract}
Information technology pushes the fourth Industrial revolution in form of physically cyber system which connected each other in smart automation system. Business and industry have adopted new technology to increase their competitiveness, on the other side HEIs are left behind in adopting technologies. The aim of this study is to assess HEIs' readiness in adopting technology for IQAS implementation. Data used in this study consist of primary data in form of interview and observations method, participated by HEIs in West Sumatera, and secondary data from HEI's profile and accreditation results. This study using Technometric Model and Analytical Hierarchy Process (AHP) approach in assessing the technology level. Technometrics model used to measure the contribution of technology components, namely Technoware, Humanware Inforware, and Orgaware. These four components used to measure technology contribution coefficient (TCC). The TCC classification is used as a basis to asses HEIs readiness. The results are presented by radar chart with 4 axes of THIO diagram based on institution type, ownership, area, and accreditation. Technoware in most of HEIs is ready. Whereas the forward is not yet ready. Infowars development requires organization involvement, through leadership commitment. Humanware needs to be improved first to support inforware and orgaware development.
\end{abstract}

Keywords: Technology adoption, technology assessment, Internal Quality Assurance System, vocational education, Technometrics model, information system

\section{Introduction}

The fourth Industrial revolution fundamentally influences all aspects of our life. Information technology pushes the fourth Industrial revolution in form of physically cyber system which connected each other in smart automation system [1]. 
Business and industry have adopted new technology to increase their competitiveness, on the other side HEIs are left behind in adopting technologies. HEIs still use old technology inactivity of teaching, learning, and management system. In this high competition world, HEIs need to adopt the rapid change of technology. The implementation of information technology has significant correlation with business efficiency and effectiveness.

Quality assurance implementation encourages continuous improvement. Without quality assurance, quality standard is not being improved. Therefore, quality assurance in educational institutions has become a matter of survival for the institution and its [2]. Internal quality assurance in higher education can be understood as the planned and systematic review of a higher education institution (HEI) to determine whether or not acceptable standards being met, maintained, and enhanced [3]. Whereas external quality assurance is an assessment activity through accreditation to determine the feasibility and level of quality achievement in HEIs.

Internal Quality Assurance System (IQAS) implementation is quite complicated. It involves entire organization lines, organizational units, and stakeholders of HEI. It handles multiple data and documents, through multiple platforms. For example, an HEI has to get and manage information about the required graduate's specs from its stakeholders, which changing overtime. This information has to be adopted in HEI's curriculum, learning process, learning technology, and new knowledge organizing to achieve up to date competences.

An information system is needed in IQAS for the availability of appropriate, adequate, accurate and reliable data. The information system greatly contributes to quality enhancement by enforcing better planning, better policymaking and better management which ultimately results better academic quality [2]. Information systems must be designed to serve the organizational needs[4].

The fourth industrial revolution Industry needs modern information system. Open software architecture which has flexible process control and development perspectives for the future is required. Different subsystems have to be connected to the integrated information landscape to provide all data in real time[9].

Information system as part of the technology has not been developed and utilized optimally by HEIs in IQAS implementation. According to Ministry of Research, Technology and Higher Education Republic of Indonesia [5], Accreditation results shows that the $6^{\text {th }}$ (Sixth) Standard: Budget allocation, facilities, infrastructure, and Information System, is one of the weakest standard of HEIs outside Javaneese Island, public HEIs and private HEIs in overall.

Therefore, one of the efforts to support IQAS implementation is assessing HEIs' readiness in adopting technology. According to UNESCAP[6], technology can be viewed as combination of four basic components that interact dynamically in a transformation process. HEIs' current technology level can be determined by measuring the contribution of all technology components, using technometric model. In this study, the results are used as a basis for assessing HEIs' readiness in adopting technology. The aim of this study are 1) to assess the readiness of Higher Education Institutions in adopting technology to support IQAS implementation, by measuring their current technology level; 2) to give recommendations about how to leverage the readiness in adopting technology in implementing Quality Assurance System.

\section{Material And Method}

\subsection{Material}

Data used in this study consist of primary data from the interview method and observations, and secondary data from HEI's profile and accreditation results. 


\subsection{Data Collecting}

Primary data was collected by interviewing the head of the Quality Assurance Unit and observations on the technical elements related to IQAS. HEIs participated in this study are HEIs in West Sumatera Province, Indonesia, that maintaining diploma programs (vocational education). The population consists of 78 HEI's. The samples for this study are 23 HEIs selected randomly by using stratified sampling based on area. They are located in 6 (six) cities and 6 (six) districts. Tabel 1 presents HEIs' classification by institution type, ownership, area, and accreditation mark.

\subsection{Data Processing}

This study using the Technometric Model and Analytical Hierarchy Process (AHP) approach in assessing the technology level. Technometrics model by UNESCAP [6] used to measure the contribution of technology components, namely Technoware, Humanware Inforware, and Orgaware.

Technoware refers to equipment, facility laboratories, and all other assets that a company can acquire or create to assist in creating a product or offering a service. Humanware refers to the capabilities of the people in the company and their capabilities to act productive manner. Inforware refers to the knowledge that is encoded in documents and processes, that are accessible to the organization easily. Orgaware refers to the description of capabilities to organize that are derived from the structure and the processes that determine how it operates[7]. These four components used to measure the combined contribution (technology contribution coefficient / TCC) in a process of transformation in IQAS implementation. AHP used to determine the component intensity.

The technometric model by UNESCAP[6] were developed by several steps. as follows:

1. Determine the sophistication degree, using certain scoring procedure. Table 1 present technology components and the sophistication degree.

2. Determine lower limit and upper limit for each of technology components. (score range 19)

3. Calculate state-of-the-art ratings of each of technology components (score range 1-10).

$S T_{i}=\frac{1}{10} \frac{\sum_{k} t_{i k}}{k_{i}} k=1,2, \ldots k_{i}$

$S T_{i}$ is the state-of-the-art of Technoware item- $i$

$t_{i k}$ is the value of criteria- $k$ from Technoware item- $i$

$S H_{j}=\frac{1}{10} \frac{\sum_{l} h_{j l}}{l_{j}} \quad l=1,2, \ldots l_{j}$

$\mathrm{SH}_{j}$ is state-of-the-art of Humanware category-j

$h_{j l}$ is the value of criteria- $l$ from Humanware category- $j$

$S l_{m}=\frac{1}{10} \frac{\sum_{n} f_{m n}}{n_{m}} \quad n=1,2, \ldots n_{m}$

$S I_{m}$ is state-of-the-art of Inforware category- $m$

$f_{m n}$ is the value of criteria- $n$ from info ware category- $m$

$S O=\frac{1}{10} \frac{\sum_{n} O_{n}}{n_{o}} \quad \mathrm{n}=1,2, \ldots \mathrm{n}_{\mathrm{o}}$
$S O_{m}$ is state-of-the-art of Orgaware

$\mathrm{O}_{n}$ is the value of criteria- $n$ of Orgaware

4. Calculate the contribution component.

$$
\begin{aligned}
& \mathrm{T}_{\mathrm{i}}=1 / 9\left[\mathrm{LH}_{\mathrm{i}}+\mathrm{STI}\left(\mathrm{UT}_{\mathrm{i}}-\mathrm{LT}_{\mathrm{i}}\right)\right] \\
& \mathrm{H}_{\mathrm{j}}=1 / 9\left[\mathrm{LH}_{\mathrm{i}}+\mathrm{STI}\left(\mathrm{UH}_{\mathrm{i}}-\mathrm{LH}_{\mathrm{i}}\right)\right]
\end{aligned}
$$




$$
\begin{aligned}
& \mathrm{I}_{\mathrm{j}}=1 / 9\left[\mathrm{LI}_{\mathrm{i}}+\mathrm{STI}\left(\mathrm{UH}_{\mathrm{i}}-\mathrm{LI}_{\mathrm{i}}\right)\right] \\
& \mathrm{O}=\frac{\sum U_{i} T_{i}}{\sum U_{i}} \\
& \mathrm{H}=\frac{\sum V_{j} H_{j}}{\sum V_{j}} \\
& \mathrm{I}=\frac{\sum W_{k} I_{k}}{\sum W_{k}} \\
& U_{i,,} V_{j} \text { and } W_{k} \text { are the weights of } T_{i}, H_{j} \text { and } I_{k}
\end{aligned}
$$

5. Calculate the component intensity. It can be done by using AHP approach.

6. Calculate Technology Contribution Coefficient (TCC).

$T C C=T^{\beta} t \times H^{\beta} h \times I^{\beta} i x O^{\beta} O$

7. Present the interpretation of the calculations result in THIO diagram.

Table 3 presents assesment based on TCC range.

\section{Results and Discussion}

According to UNESCAP [6], criteria for each component technology are presented in Table 4. The item or category used in assesment are presented in Table 5. Table 6 presents HEIs' technology level assesment results.

\subsection{Technoware $(\mathrm{T})$}

Most of HEIs has moderate to high value in this technology component in all kind of facilities from data collecting, storing, processing to data presentations and information distribution facilities. This is especially happens to public HEIs. Whereas most of private HEIs tend to have less capability to cope with the rapid change of facilities technology requirements. Among of HEIs that are already well equipped, some of them still need to increase the capabilities of some facilities to meet the needs of their institution in some areas. For example: increasing internet bandwidth of information distribution facilities.

For some other HEIs with orgaware still left behind, there are two ways to be considered of addressing this issue: first, building or acquiring the needed facilities from the beginning with well design approach; second, utilizing cloud computing facilities to reduce costs of acquisition or ownership of hardware, software and skilled resources and also to increase speed of data transfer.

\subsection{Humanware (H)}

Humanware component technology is related to quantity and qualification needed in IQAS implementation. The highest value in orgaware is gotten by HEIs with good leadership in management level, supported by skillful teamwork. Among them, there are visioner head of quality assurance unit with good quality management knowledge and skill; creative staff of quality assurance unit; discipline, efficient and well organized of administration staff with good services, etc. The lowest value of humanware is gotten by HEIs with low values in some criterias, mostly are as follows:

a) in administration staff, due to the lack of staff with administration skill required for quality assurance implimentation.

b) in information technology staff, due to the lack of staff with system development skill. 
c) in management level (head of QA unit, head of IT unit, coordinator of study programmes), due to the lack of comprehensive understanding of quality management.

Humanware is the executor of the other technology components. Some humanware readiness need to be done are: 1) behaviour; 2) achievement motivation 3) technical skill; 4) willingness to adopt new technology; 5) mind set of continues learning; and 6) continues improvement. The accomplishment of technology adoption begins with humanware.

Table 1 HEIs classification

\begin{tabular}{|c|c|c|c|c|c|c|c|c|}
\hline TYPE & & Academy & Institute & Polytechnic & College & University & TOTAL & $\%$ \\
\hline \multirow{2}{*}{ OWNERSHIP } & Private & 8 & 1 & 0 & 3 & 3 & 15 & $65 \%$ \\
\hline & Public & 0 & 2 & 4 & 0 & 2 & 8 & $35 \%$ \\
\hline \multirow{2}{*}{ AREA } & District & 2 & 2 & 1 & 1 & 0 & 6 & $26 \%$ \\
\hline & City & 6 & 1 & 3 & 2 & 5 & 17 & $74 \%$ \\
\hline \multirow{4}{*}{ ACCREDITATION } & A & 0 & 0 & 0 & 0 & 2 & 2 & $9 \%$ \\
\hline & $\mathrm{B}$ & 2 & 3 & 2 & 1 & 2 & 10 & $43 \%$ \\
\hline & $\begin{array}{l}\mathrm{C} \\
\text { In }\end{array}$ & 6 & 0 & 0 & 0 & 0 & 6 & $26 \%$ \\
\hline & Process & 0 & 0 & 2 & 2 & 1 & 5 & $22 \%$ \\
\hline TOTAL & & 8 & 3 & 4 & 3 & 5 & 23 & $100 \%$ \\
\hline
\end{tabular}

Table 2. Technology components sophistication degree

\begin{tabular}{|c|c|c|c|c|}
\hline Technoware & Humanware & Inforware & Orgaware & Score \\
\hline Manual facilities & Operating abilities & Familiarizing facts & Striving framework & 123 \\
\hline Powered facilities & Setting Up abilities & Describing facts & Tie-Up framework & 234 \\
\hline General purpose facilities & Repairing Abilities & Specifying facts & Venturing framework & 345 \\
\hline Special purpose facilities & Reproducing abilities & Utilizing facts & Protecting framework & 567 \\
\hline Automatic facilities & Adapting abilities & Comprehending facts & Stabilizing framework & 678 \\
\hline Computerized facilities & Improving abilities & Generalizing facts & Prospecting framework & 789 \\
\hline Integrated Facilities & Innovating abilities & Assessing facts & Leading framework & 8910 \\
\hline
\end{tabular}

Table 3 Qualitative Assessment Based On TCC range

\begin{tabular}{ll}
\hline Range Of TCC & TCC Value Classification \\
\hline $0<$ TCC $<0,1$ & Very Low \\
$0,1<$ TCC $\leq 0,3$ & Low \\
$0,3<$ TCC $\leq 0,5$ & Standard \\
$0,5<$ TCC $\leq 0,7$ & Good \\
$0,7<$ TCC $\leq 0,9$ & Very Good \\
$0,9<$ TCC $\leq 1,0$ & Absolute Sophisticated \\
\hline
\end{tabular}


Table 4 Component Technology's Criteria

\begin{tabular}{ll}
\hline Technology Component & Criteria \\
\hline Technoware & Scope \\
& Precision \\
& Handling \\
& Control \\
& Contribution \\
\hline Humanware & Creativity \\
& Achievement Motivation \\
& Orientation to Cooperate \\
& Orientation to Efficiency \\
& Discipline \\
\hline Infoware & Information Retrieval \\
& Information relevance \\
& Information Updates \\
& Ease of Communication \\
\hline Orgaware & Leadership effectiveness \\
& Work autonomy \\
& organization direction \\
& personnel involvement \\
& orientation to stakeholder innovation climate \\
organization integration
\end{tabular}

Table 5 Component Technology"s Item / Category

\begin{tabular}{ll}
\hline Technology & Item / Category \\
Component & \\
\hline Technoware & Data collection facilities \\
& Data storing facilities \\
& Data processing facilities \\
& Data presentatios facilities \\
& Information distributing facilities \\
\hline Humanware & Head of Quality Assurance Unit \\
& Head of Information Technology Unit \\
& Coordinator of Study Programmes \\
& Quality Assurance Unit Staffs \\
& Information Technology Staffs \\
& Administration Staffs \\
& Lecturers \\
\hline Inforware & Standard Planning phase \\
& Standard Implementation phase \\
& Standard (Implementation) Evaluation phase \\
& Standard (Implementation) Controlling phase \\
& Standard Improvement phase \\
\hline Orgaware & (institution level) \\
\hline
\end{tabular}


Table 6. HEIs' technology level

\begin{tabular}{|c|c|c|c|c|c|}
\hline HEIs & Techno ware & Human ware & Infor ware & Orga ware & TCC \\
\hline 1 & 0,662 & 0,556 & 0,386 & 0,670 & 0,668 \\
\hline 2 & 0,624 & 0,547 & 0,389 & 0,632 & 0,655 \\
\hline 3 & 0,647 & 0,561 & 0,372 & 0,372 & 0,655 \\
\hline 4 & 0,656 & 0,558 & 0,366 & 0,635 & 0,652 \\
\hline 5 & 0,642 & 0,554 & 0,372 & 0,625 & 0,650 \\
\hline 6 & 0,627 & 0,540 & 0,374 & 0,625 & 0,647 \\
\hline 7 & 0,645 & 0,557 & 0,359 & 0,629 & 0,647 \\
\hline 8 & 0,593 & 0,556 & 0,371 & 0,625 & 0,646 \\
\hline 9 & 0,636 & 0,553 & 0,358 & 0,619 & 0,642 \\
\hline 10 & 0,662 & 0,555 & 0,344 & 0,625 & 0,641 \\
\hline 11 & 0,634 & 0,561 & 0,338 & 0,629 & 0,639 \\
\hline 12 & 0,630 & 0,543 & 0,341 & 0,613 & 0,632 \\
\hline 13 & 0,500 & 0,548 & 0,326 & 0,575 & 0,608 \\
\hline 14 & 0,500 & 0,548 & 0,326 & 0,575 & 0,608 \\
\hline 15 & 0,471 & 0,500 & 0,293 & 0,456 & 0,550 \\
\hline 16 & 0,500 & 0,441 & 0,284 & 0,456 & 0,539 \\
\hline 17 & 0,406 & 0,408 & 0,281 & 0,285 & 0,464 \\
\hline 18 & 0,431 & 0,411 & 0,258 & 0,285 & 0,458 \\
\hline 19 & 0,431 & 0,410 & 0,258 & 0,285 & 0,458 \\
\hline 20 & 0,431 & 0,406 & 0,258 & 0,285 & 0,457 \\
\hline 21 & 0,410 & 0,411 & 0,222 & 0,285 & 0,443 \\
\hline 22 & 0,431 & 0,406 & 0,209 & 0,227 & 0,413 \\
\hline 23 & 0,246 & 0,412 & 0,209 & 0,227 & 0,398 \\
\hline
\end{tabular}




\subsection{Inforware (I)}

Inforware got the lowest value among other technology components. It shows that information has not managed well by HEIs in implementing IQAS, although the technoware value is high, means the supported facilities are available.

The highest value in inforware gained by HEIs that perform the whole phases of IQAS, and manage data and information along the way. The lowest value indicates unproper implementation of IQAS.

Yet, in overall, the supported mechanism still (1) not enabling good information retrieval to IQAS documents such as policies, standards, manuals, and forms; (2) not enabling interoperability with HEIs' business process data to collect standards implementation data, easily; (3) not enabling relevance data sorting to build clearly defined tasks and responsibilities. (4) not enabling of getting the most updated information by real time evaluation of standards implementation (5) not enabling timely distribution of information easily, such as audit schedules, audit results, and meetings. (6) not enabling survey data become feedback and decision making sources, easily. These difficulties caused by technical barriers. It is due to the technology architecture or system development method which is not allowing easy integration and collaborations among different systems or different platforms[8].

\subsection{Orgaware $(\mathbf{O})$}

All of HEIs participated in this study, already have agency or unit or team, or at least person that is dedicated for quality assurance system. The highest value of orgaware is gotten by institution with good organization direction. This institution has direction of qualities to be achieved and how they can be achieved. This direction comes from top management, being implemented by operational team and then assured by the quality assurance unit. The lowest value is gotten by institution with poor organization direction. This institution has not yet has direction of qualities to be achieved and how they can be achieved. This institution has low work specialization, meaning the personnel in charged for quality assurance unit also do other task or job. It also happens in other work area, for example: The personnel in charged for coordinator of study programmes need to do administration work.

\subsection{THIO Diagram}

THIO diagram based on institution type, ownership, area, accreditation are presented consecutively in Figure1- 4.

Figure 1 presents THIO diagram based on institution ownership (public/private). It shows significant difference between technology level of public HEIs and private HEIs in all components. Most of respondents from private HEI's stated that they have a limited budget to achieve higher standars. 


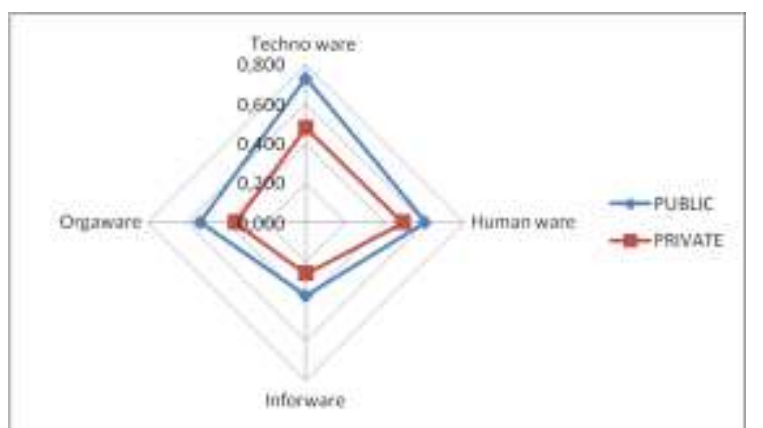

Figure 1. THIO diagram based on institution ownership

Figure 2 presents THIO diagram based on institution type (academy, polytechnic, institute, college, university). It shows that academy got the lowest value in all componens technology. However, there is no big differences between technology component values of polytechnic, institute, college, and university. As described in Table 1, academies are $100 \%$ private HEIs, so in Figure 1, the difference between technology level of public HEIs and private HEIs, mostly influenced by academy's. In West Sumatera Province, academy tend to be less desirable, so it is less promising economically.

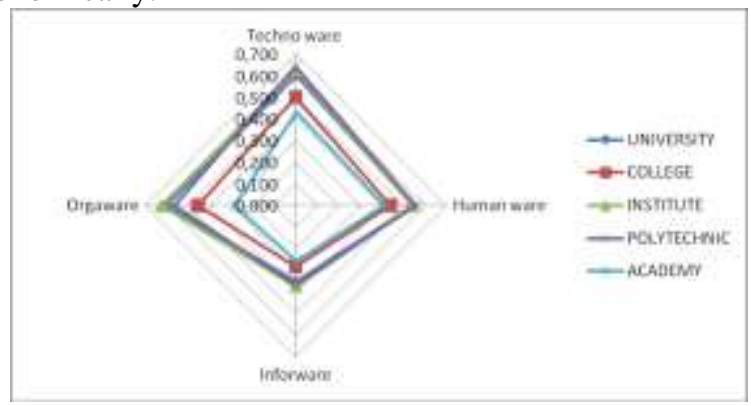

Figure 2. THIO diagram based on HEI's type

Figure 3 presents THIO diagram based on area (district/city). It shows no significant difference between technology level of HEIs located in district and located in city.

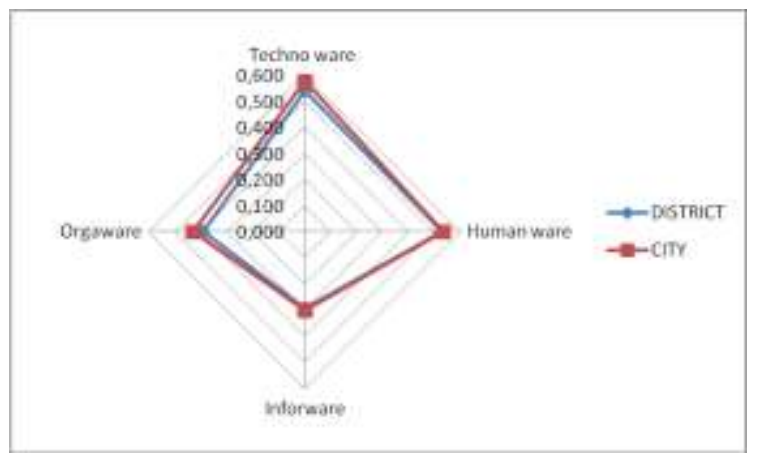

Figure 3. THIO diagram based on area 
Based on institution accreditation marks, about $9 \%$ HEIs got ' $A$ ' marks, $43 \%$ got ' $B$ ' marks, $26 \%$ got ' $\mathrm{C}$ ' marks and $22 \%$ have been in process of accreditation. Figure 4 presents diagram THIO based on accreditation marks, by ommitting those which have been in process of accreditation. The diagram shows positive correlation between the four technology components values with accreditation marks.

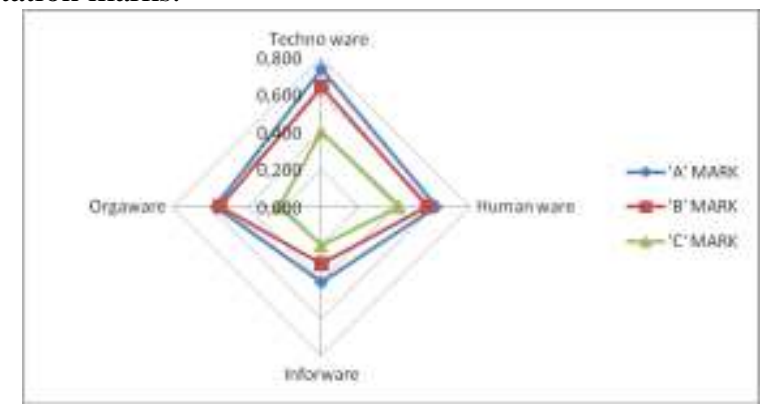

Figure 4. THIO diagram based on accreditation marks

\subsection{Technology Contribution Coefficient (TCC)}

Based on the TCC range in Table 2 , about $61 \%$ of HEIs are in "good" mark $(0,5<$ TCC $\leq$ $0,7)$, and the rest of them are in "standard" mark $(0,3<\mathrm{TCC} \leq 0,5)$ of technology level. In this study, the TCC classification is used as a basis to asses HEIs readiness in adopting technology for IQAS implementation.

\section{Conclusions}

Facing the fourth Industrial revolution challenge, HEI's has to adopt technology of automation, cloud computing, etc. After assessing Institution Readiness in Adopting Technology in this research can be concluded that HEIs are not yet ready. Technoware in most of HEIs is ready, Orgaware readiness in adopting technology has to be improved to be well planned and more professional in management. Whereas the inforware is not yet ready. Inforware development requires organization involvement, through leadership commitment in encouraging the development of well designed and sustainable information systems. It is related to humanware and orgaware readiness. The lack of understanding about the quality assurance system comprehensively causes unreadiness of inforware. Technology architecture and system development approach being used also become technical barriers. Humanware needs to be improved first to support inforware and orgaware development.

\section{Acknowledgements}

We would like to thank all HEIs that participated in this study, and also to our family, friends, lecturer fellows and students for the helps and supports.

\section{References}

[1] B. Denkena and T. Morke, Cyber-Physical and Gentelligent Systems in Manufacturing and Life Cycle: Genetics and Intelligence-Keys to Industry 4.0. Cambridge: Academic Press, 2017. 
[2] S. M. W. Ali, "Strategic Requirements of Higher Education Management Information System," Collnet J. Sci. Inf. Manag., vol. 5, no. 2, pp. 145-155, 2011.

[3] W. Daguang, X. Zuoxu, W. Fan, and Q. Yanjie, Enhancing Teaching and Learning through Internal Quality Assurance. Paris: International Institute for Educational Planning, 2017.

[4] K. C. Laudon and J. P. Laudon, "Managing the digital firm," in Managing Information Systems, London: Pearson Education, 2004.

[5] Direktur Penjaminan Mutu Direktorat Pembelajaran Dan Kemahasiswaan Kemenristekdikti, "Kebijakan Nasional Sistem Penjaminanmutu Perguruan Tinggi di Indonesia," 2016.

[6] United Nations Economic and Social Commission for Asia and the Pacific (UNESCAP), Technology Atlas Project: An Overview of Framework for Technology-Based Development. New York: United Nations, 1989.

[7] R. Smith and N. Sharif, "Understanding and acquiring technology assets for global competition," Technovation, vol. 27, no. 11, pp. 643-649, Nov. 2007.

[8] S. Syahril and Y. Yulherniwati, "Sustainability of Information Technology in Higher Education Institutions: New Concept," in Proceedings of the 3rd UPI International Conference on Technical and Vocational Education and Training, 2015. 